\title{
INCORPORAÇÃO DE ERITROMICINA A MEMBRANAS DE QUITOSANA COMPLEXADA COM ALGINATO OU XANTANA PARA A APLICAÇÃO NO TRATAMENTO DE LESÕES DE PELE
}

\author{
RENATA. F. B. de SOUZA, FERNANDA C. B. de SOUZA e ÂNGELA M. MORAES \\ Universidade Estadual de Campinas, Faculdade de Engenharia Química, \\ Departamento de Engenharia de Materiais e Bioprocessos \\ E-mail para contato: ammoraes@ @eq.unicamp.br
}

\begin{abstract}
RESUMO - A quitosana (Q), o alginato (A) e a xantana (X) são polímeros biodegradáveis e biocompatíveis muito utilizados na obtenção de curativos, podendo ser combinados entre si e com outros compostos ativos, tornando-se mais efetivos no processo de cura de uma lesão. Este trabalho visou à produção de filmes constituídos de Q complexada com A ou X incorporando diferentes proporções do antibiótico eritromicina por dois métodos distintos, adição direta à mistura polimérica (AD) e impregnação em solução etanólica contendo o composto ativo (IE). Os filmes obtidos foram caracterizados quanto ao seu aspecto e morfologia. A eficiência de incorporação do composto ativo foi determinada, bem como sua cinética de liberação a partir dos dispositivos. Observou-se que a introdução do composto na matriz não promoveu alterações em seu aspecto visual. Pelo método $\mathrm{AD}$, a eficiência de incorporação máxima $\left(\mathrm{E}_{\max }\right)$, de $54 \%$, deu-se para o filme Q-X, alcançando-se a razão $35 \mathrm{mg}$ droga/g de membrana. Pelo método IE atingiu-se $\mathrm{E}_{\max }$ igual a $20 \%$ para ambas as formulações, resultando em razões mássicas droga/membrana muito superiores, de $0,7 \mathrm{~g} / \mathrm{g}$ para Q-A e $2,1 \mathrm{~g} / \mathrm{g}$ para Q-X. Devido ao tamanho relativamente grande da molécula de eritromicina, sua liberação das matrizes foi lenta. Logo, os dispositivos obtidos podem atuar como agentes de liberação por longos períodos, exigindo assim trocas menos frequentes e resultando em tratamento menos traumático e mais confortável para o paciente.
\end{abstract}

\section{INTRODUÇÃO}

A pele é considerada o maior órgão do corpo humano e apresenta importantes funções, tais como barreira de proteção contra impactos mecânicos, ataques químicos ou microbianos e regulação homeostática do organismo. Quando a pele é lesionada suas funções ficam comprometidas e, portanto, é importante que se garanta uma cicatrização adequada da área afetada a fim de que não haja danos à saúde do indivíduo (Penzer e Ersser, 2010). O uso de curativos no tratamento de lesões de pele é uma técnica antiga, que proporciona resultados rápidos e eficientes. Nos últimos anos, tornou-se evidente a evolução desta técnica, e uma ampla gama de curativos vem sendo desenvolvida (Ovington, 2007). Devido a sua biodegradabilidade e biocompatibilidade, diversos polímeros naturais ou sintéticos são 
utilizados como matérias-primas para a produção de dispositivos para esta finalidade (Dias $e t$ al., 2011). Dentre os primeiros destacam-se a quitosana, o alginato e a xantana.

A quitosana é um biopolímero linear obtido por meio da desacetilação da quitina, um composto encontrado em crustáceos, além de outras fontes. É composta de unidades de glucosamina e N-acetil-glucosamina. Em baixos valores de $\mathrm{pH}$, a quitosana pode se comportar como um policátion e é capaz de interagir com polímeros negativamente carregados, formando os chamados complexos polieletrólitos (PECs) (Croisier e Jérôme, 2013). O alginato é um polissacarídeo linear aniônico natural extraído de algas marrons, cuja estrutura é composta de dois tipos de subunidades repetitivas denominadas (1,4)- $\beta$-Dmanuronato (bloco M) e (1,4)- $\alpha$-L-guluronato (bloco G) (Lee e Mooney, 2012). Já a xantana é um polissacarídeo aniônico natural produzido pela bactéria Xanthomonas campestris, com uma estrutura primária que consiste de unidades de pentassacarídeos formada por duas unidades de glicose, duas de manose e uma de ácido glicurônico (Coviello et al., 2007). Estes biopolímeros podem ser combinados para dar origem a materiais com propriedades superiores às daqueles constituídos dos polímeros isolados.

Compostos ativos podem ser adicionados aos dispositivos constituídos destes biopolímeros, tornando-os assim vantajosos em relação aos curativos tradicionais por serem capazes de atuar como sistemas de liberação controlada e, portanto, acelerar o processo de cura (Zahedi et al., 2010; Lima, 2012). Exemplos destes compostos são os antibióticos, como é o caso da eritromicina, um composto da família dos macrolídeos produzido pela bactéria Streptomyces erythreus, pouco solúvel em água, mas bastante solúvel em etanol. Dentre suas principais aplicações encontra-se o tratamento de infecções de pele (Schönfeld e Kirst, 2002).

Neste contexto, este trabalho teve por objetivo a produção de membranas poliméricas constituídas de complexos de quitosana com alginato e com xantana incorporando eritromicina, a fim de se obter sistemas de liberação controlada capazes de atuar de maneira mais eficiente na terapia de lesões de pele.

\section{MATERIAIS E MÉTODOS}

\subsection{Materiais}

Para a obtenção e caracterização dos dispositivos, foram utilizados os seguintes reagentes, de qualidade analítica certificada: quitosana de carapaça de camarão com grau de desacetilação mínimo de 75\%, (lote $\mathrm{n}^{\circ} 061 \mathrm{M} 0046 \mathrm{~V}$ ), alginato de sódio de baixa viscosidade obtido de algas marrons (lote $\mathrm{n}^{\circ}$ 090M0092V), xantana (lote $\mathrm{n}^{\circ} 108 \mathrm{~K} 0038$ ) e eritromicina da Sigma-Aldrich Co.; etanol e ácido acético glacial da Synth; cloreto de cálcio di-hidratado e hidróxido de sódio da Merck \& Co. Inc. A água utilizada nos ensaios foi destilada e deionizada em sistema Milli-Q® da Millipore.

\subsection{Métodos}

Preparação das membranas: As membranas foram preparadas com base nos procedimentos descritos por Rodrigues et al. (2008), Bueno e Moraes (2011) e Veiga (2012). A metodologia tem como base a formação dos complexos polieletrólitos Q-A e Q-X pela mistura dos polímeros em reator, seguida de sua desaeração, moldagem e posterior secagem. 
A incorporação do composto ativo foi realizada pela adição direta do antibiótico à mistura de polissacarídeos no reator nas proporções de 20,40 e $60 \mathrm{mg}$ de eritromicina por grama de biopolímeros, e também pela impregnação de amostras de $1 \mathrm{~cm}$ x $1 \mathrm{~cm}$ dos filmes em $4 \mathrm{~mL}$ de solução etanólica contendo eritromicina nas concentrações de 1,3 e $5 \mathrm{mg} / \mathrm{m}$ durante uma hora, sob temperatura de $25^{\circ} \mathrm{C}$ e agitação de $100 \mathrm{rpm}$.

Caracterização das membranas: As membranas foram inspecionadas quanto ao aspecto a olho nu e fotografadas com câmera digital (modelo A410, Canon). Sua morfologia foi avaliada através de microscopia eletrônica de varredura (MEV) em microscópio (modelo LEO 440, Leica). Para isso, utilizou-se amostras de dimensões de $2 \mathrm{~cm}$ x $1 \mathrm{~cm}$ previamente metalizadas com uma fina camada de ouro de espessura de 92 A (mini Sputter coater, SC 7620). Para determinação de sua morfologia transversal, as membranas foram previamente criofraturadas com nitrogênio líquido.

Para a medida da eficiência de incorporação de eritromicina nas membranas pelo método $\mathrm{AD}$, as soluções provenientes da lavagem das membranas foram evaporadas em estufa a $37{ }^{\circ} \mathrm{C}$ por 20 horas. Após o término deste período, o resíduo remanescente no recipiente foi ressolubilizado em etanol e a solução obtida foi filtrada com filtro de porosidade $0,45 \mu \mathrm{m}$. A eritromicina no filtrado foi quantificada por espectrofotometria a $205 \mathrm{~nm}$. O mesmo foi feito para as placas de poliestireno. Este procedimento foi realizado também para membranas isentas de eritromicina, a fim de se quantificar compostos extratíveis em etanol que não fossem o composto de interesse. Uma vez determinada a quantidade de eritromicina perdida durante o processo, e conhecendo-se a quantidade inicial de eritromicina adicionada à membrana $\left(\mathrm{m}_{\mathrm{c}, \mathrm{i}}\right)$, tem-se a quantidade final de composto retido no filme $\left(\mathrm{m}_{\mathrm{c}, \mathrm{m}}\right)$, e a eficiência de incorporação $(\varepsilon)$ pôde ser então calculada pela Equação 1:

$$
\varepsilon=\frac{m_{C, m}}{m_{C, i}} \times 100 \%
$$

Para o cálculo da eficiência de incorporação de antibiótico incorporado pelo método IE, logo após o fim do período de incubação das membranas, a quantidade de eritromicina presente na solução etanólica remanescente foi determinada por espectrofotometria a $205 \mathrm{~nm}$. Com esse valor foi possível calcular a quantidade de composto que não foi incorporado à membrana. Este procedimento foi realizado também para membranas que não continham eritromicina. Como a concentração inicial da solução etanólica de incorporação é conhecida, a eficiência de incorporação pôde ser calculada também pela Equação 1.

Já para a avaliação da cinética de liberação do antibiótico foram utilizadas amostras de membranas de $1 \mathrm{~cm} \times 1 \mathrm{~cm}$. Os corpos de prova foram pesados e colocados em frascos contendo 3,0 mL de tampão fosfato-salina (PBS) sob agitação de $100 \mathrm{rpm}$ e temperatura de $37^{\circ} \mathrm{C}$. Cada conjunto de amostras foi analisado em períodos de tempo pré-determinados. Para isso, o conteúdo dos frascos era analisado quanto à concentração do composto ativo por espectrofotometria utilizando-se o método descrito por Ford et al. (1953).

\section{RESULTADOS E DISCUSSÃO}

$\mathrm{Na}$ Figura 1 se encontram os resultados para a eficiência de incorporação obtidos quando se utilizou o método $\mathrm{AD}$. Observa-se que para ambas as formulações, os valores de 
eficiência de incorporação podem ser considerados satisfatórios, ficando entre 42 e 54\%. Uma eficiência maior não foi obtida provavelmente porque grande parte das partículas de eritromicina adicionadas à mistura ficaram somente depositadas na matriz da membrana formada, acumulando-se preferencialmente na superfície voltada para a placa ou para o ar, o que pode ter ocorrido devido à falta de afinidade do composto pelas matrizes hidrofílicas. Essas partículas podem ter sido arrastadas durante a lavagem das membranas e por isso verificou-se perda apreciável de eritromicina nesta etapa.

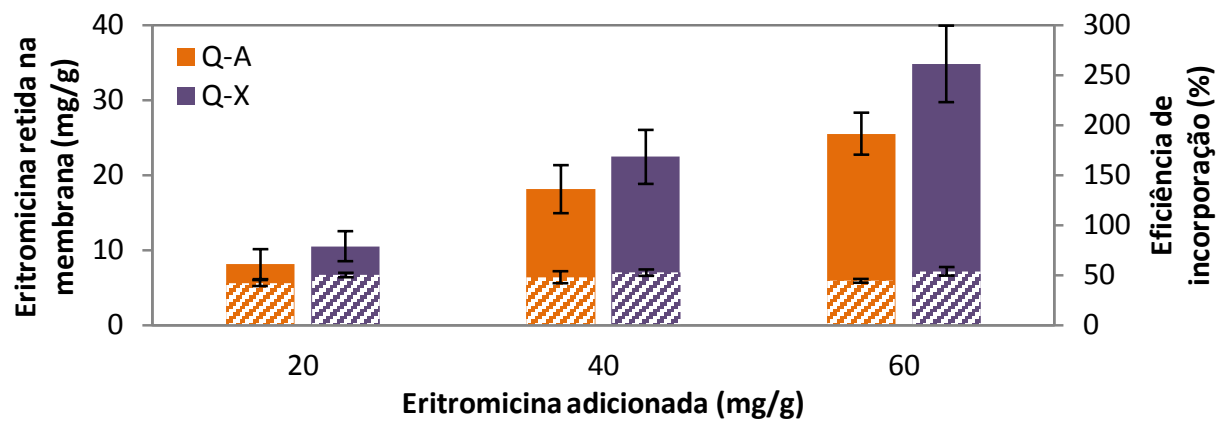

Figura 1: Dados referentes à incorporação de eritromicina a membranas de Q-A e Q-X pelo método da adição direta à mistura polimérica, em termos de $\mathrm{mg}_{\text {droga }} / \mathrm{g}_{\text {membrana }}$ (barras preenchidas) e de percentagem (barras hachuradas).

Já na Figura 2 são apresentados os resultados da eficiência de incorporação do antibiótico às membranas pelo método IE. Observa-se que, embora eficiências mais baixas de incorporação tenham sido obtidas para este método, maior quantidade do composto ficou retida em relação ao outro método estudado, para ambas as formulações. Pode-se afirmar que a formulação de Q-X foi capaz de reter maior quantidade de eritromicina. O mesmo comportamento foi observado no trabalho de Veiga (2012), no qual a autora destacou a possibilidade de se reaproveitar o fármaco remanescente na solução de impregnação para processos posteriores, aumentando dessa forma a eficiência global do processo.

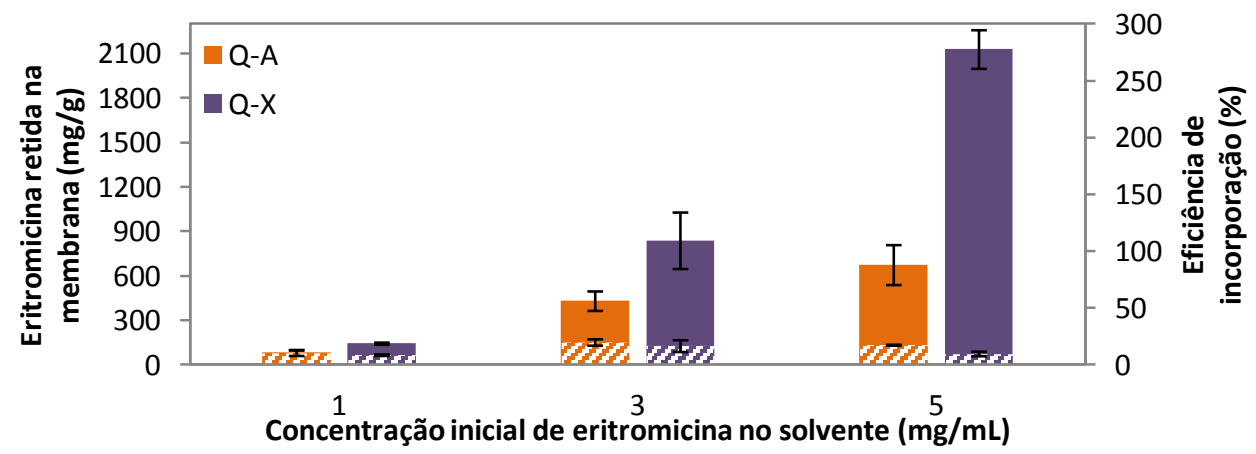

Figura 2: Dados referentes à incorporação da eritromicina a membranas de Q-A e Q-X pelo método de impregnação em solução etanólica, em termos de $\mathrm{mg}_{\text {droga }} / \mathrm{g}_{\text {membrana }}$ (barras preenchidas) e de percentagem (barras hachuradas).

As caracterizações apresentadas a seguir são referentes às formulações contendo maior quantidade de composto ativo para cada um dos métodos de incorporação utilizados, ou seja, filmes de Q-A e Q-X aos quais se adicionou $60 \mathrm{mg}_{\text {eritromicina }} / \mathrm{g}_{\text {membrana }}$ pelo método $\mathrm{AD}$ e também filmes de Q-A e Q-X aos quais se incorporou o antibiótico utilizando-se o método IE com solução de concentração $5 \mathrm{mg} / \mathrm{mL}$. 
Na Figura 3 é apresentado o aspecto visual das membranas de Q-A e Q-X isentas de eritromicina ou às quais o composto foi incorporado pelo método $\mathrm{AD}$.
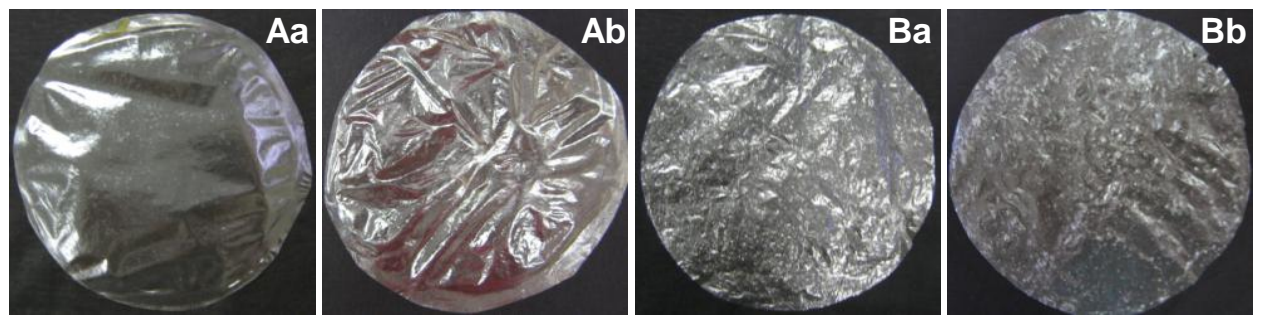

Figura 3: Aspecto visual das membranas de quitosana e alginato (A) e quitosana e xantana (B) isentas de eritromicina (a) e às quais se incorporou o antibiótico pelo método de adição direta à mistura polimérica na proporção de $60 \mathrm{mg} / \mathrm{g}$ (b).

É possível observar que a membrana de Q-A apresenta superfície mais lisa e aspecto menos opaco que a membrana de Q-X isenta do composto ativo. Além disso, os filmes de Q$\mathrm{X}$ possuem fibras poliméricas ao longo de sua estrutura. Não houve alteração considerável no aspecto destas membranas em relação àquelas isentas do antibiótico, já que a superfície mais ondulada obtida em ambos os casos é decorrente do processo de secagem, que ocorre de forma distinta para cada membrana produzida. Portanto, pode-se dizer que a presença do agente ativo não afeta a propriedade analisada.

Pela análise da morfologia da superfície e seção transversal das membranas, apresentada nas Figuras 4 e 5, é possível observar que os filmes de Q-A possuem superfície levemente rugosa, o que não é visível a olho nu, e apresentam lamelas ao longo de sua espessura. Já os filmes de Q-X possuem uma superfície ondulada e apresentam fibras ao longo de sua estrutura, sendo possível também observar a presença de lamelas, porém menos compactas em relação àquelas observadas nas membranas de Q-A.

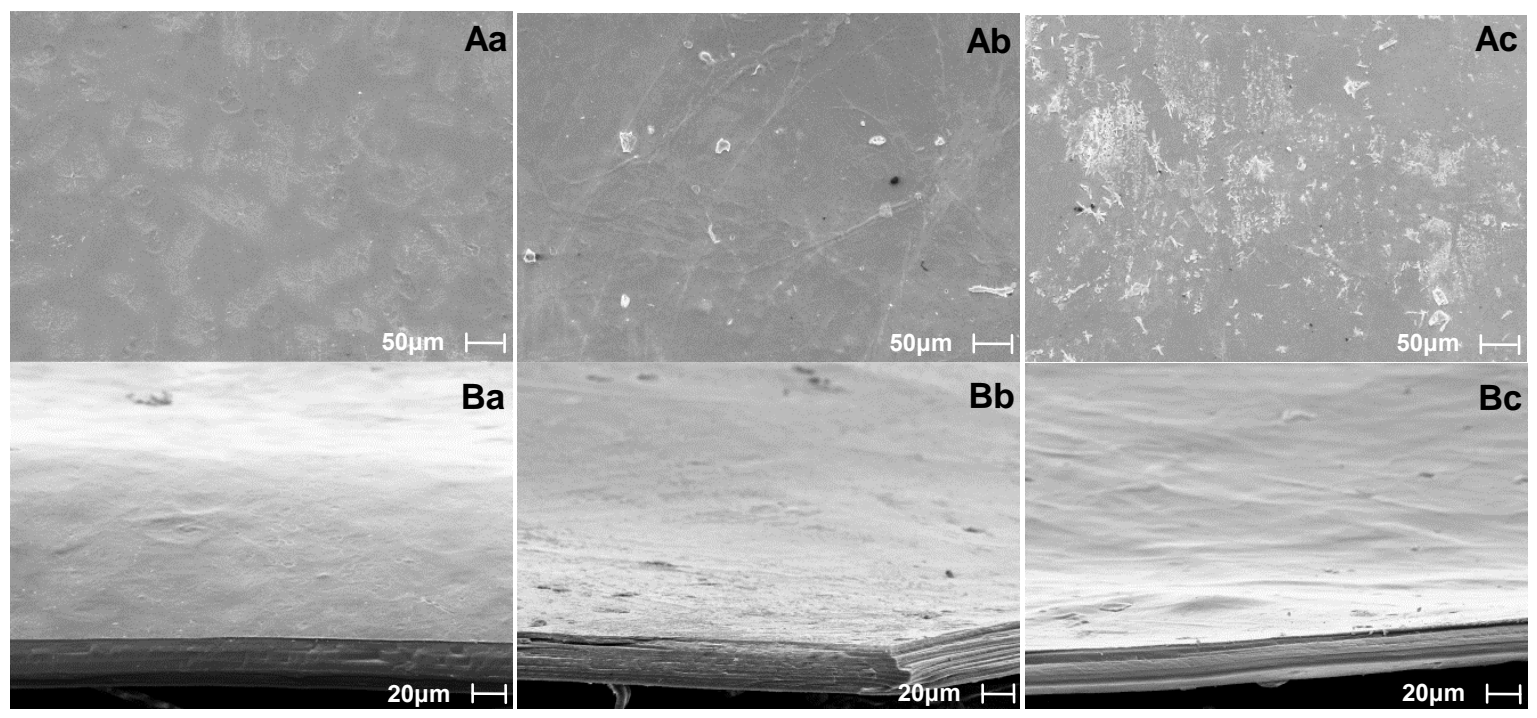

Figura 4: Morfologia da superfície (A) e da seção transversal (B) das membranas de Q-A isentas de eritromicina (a) e dos filmes aos quais o antibiótico foi incorporado por $\mathrm{AD}$, na proporção de $60 \mathrm{mg} / \mathrm{g}$ (b) e IE, com solução de concentração $5 \mathrm{mg} / \mathrm{mL}$ (c). 
Para todas as formulações estudadas contendo o composto ativo, observou-se uma distribuição não homogênea da droga na superfície dos filmes. Para a formulação de Q-A à qual a eritromicina foi incorporada pelo método da adição, verificou-se que a droga se apresenta na forma típica de seus cristais e permanece retida em maior quantidade nas superfícies voltadas para a placa utilizada no processamento ou para o ar, o que é decorrente de uma exclusão do composto da fase aquosa. No caso da formulação de Q-X o antibiótico se encontra também distribuído no interior da matriz. Para a situação na qual o composto foi incorporado pelo método da impregnação, verifica-se a presença do antibiótico na superfície da membrana de Q-A na forma de placas alongadas, decorrente do efeito de solvatomorfismo do composto na presença de etanol, enquanto que na membrana de Q-X, há também uma discreta presença do antibiótico no interior da matriz, refletindo sua maior capacidade de absorção de etanol (dado não apresentado).

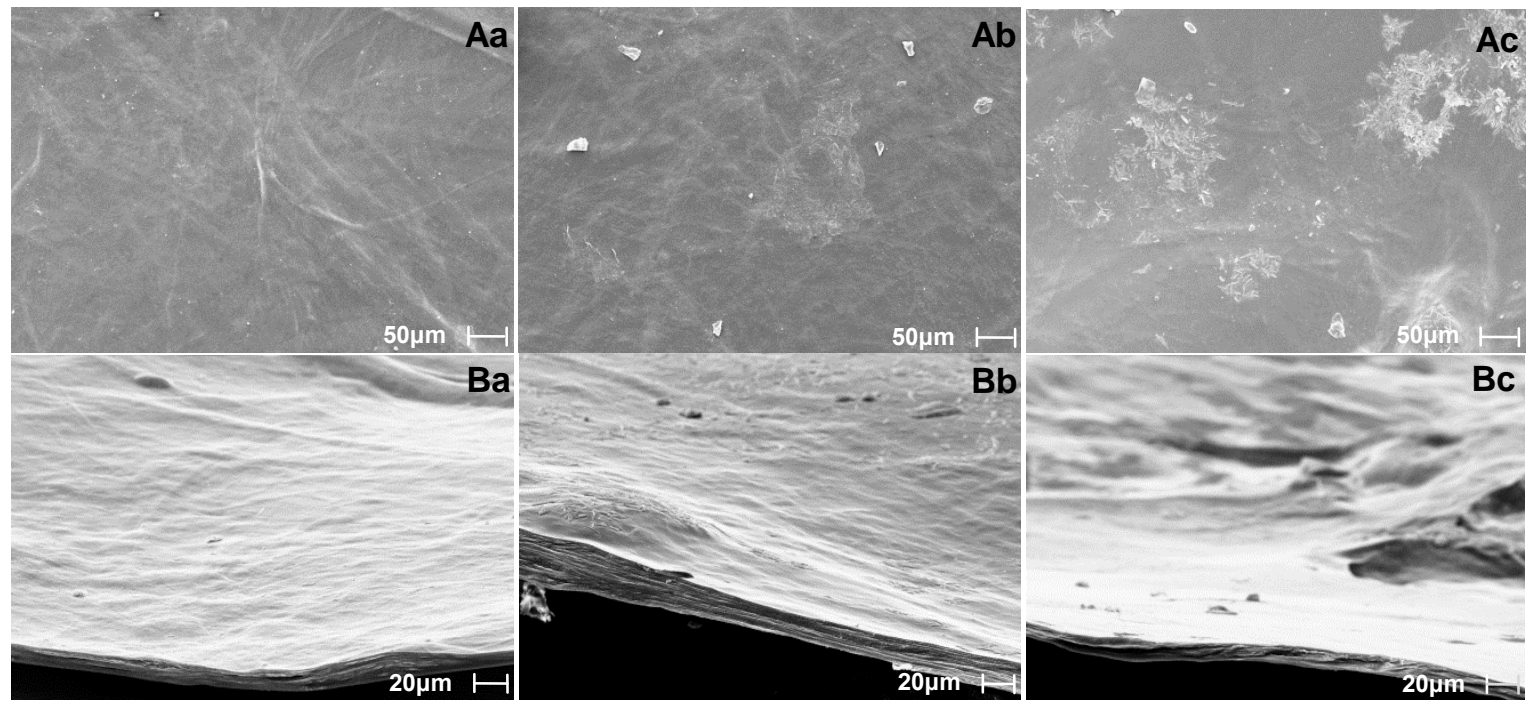

Figura 5: Morfologia da superfície (A) e da seção transversal (B) das membranas de Q-X isentas de eritromicina (a) e dos filmes aos quais o antibiótico foi incorporado por $\mathrm{AD}$, na proporção de $60 \mathrm{mg} / \mathrm{g}$ (b) e IE, com solução de concentração $5 \mathrm{mg} / \mathrm{mL}$ (c).

Na Figura 6(a) são apresentados os resultados do ensaio de liberação para os filmes de Q-X e Q-A aos quais o composto foi introduzido pelo método AD na proporção de $60 \mathrm{mg} / \mathrm{g}$, em termos da massa de composto liberada por grama de membrana e percentagem. Para ambos os casos, observa-se que a quantidade de antibiótico liberada não representa uma grande parcela do que foi inicialmente incorporado, o que pode ser atribuído à falta de afinidade do composto pelo meio aquoso. Isto significa que a força motriz para saída do mesmo da matriz é muito pequena e, provavelmente, a eritromicina liberada inicialmente corresponde àquela que se encontrava depositada na superfície. De fato, observa-se que a percentagem de droga liberada chegou a cerca de $34 \%$, o equivalente a aproximadamente $11,9 \mathrm{mg} / \mathrm{g}$ e $17 \%$, o equivalente a cerca de $4,2 \mathrm{mg} / \mathrm{g}$ para Q-X e Q-A, respectivamente.

Na Figura 6(b) são apresentados os resultados do ensaio de liberação para os filmes de Q-X e Q-A aos quais a eritromicina foi incorporada pelo método IE com solução de concentração $5 \mathrm{mg} / \mathrm{mL}$. Nota-se que a formulação de Q-X, por conter maior quantidade inicial de droga retida em sua estrutura, apresentou maior liberação do composto, sendo que, em $24 \mathrm{~h}$, cerca de $25 \mathrm{mg} / \mathrm{g}$ são liberados. No mesmo período, para a formulação de Q-A, ocorre a 
liberação de aproximadamente $11 \mathrm{mg} / \mathrm{g}$. Embora as quantidades liberadas sejam elevadas, quando comparadas àquelas obtidas para os ensaios apresentados anteriormente em tempo relativamente maior, a percentagem equivalente de liberação do composto foi de apenas 1,2\% e 1,7\% para as formulações de Q-X e Q-A, respectivamente. Observa-se que as membranas de Q-X são capazes de liberar maior quantidade do antibiótico incorporado para os dois diferentes métodos utilizados. Pode-se dizer ainda que a liberação ocorre de forma lenta e se deve, provavelmente, ao tamanho relativamente grande da molécula de eritromicina, que dificulta uma difusão mais rápida ao longo da matriz.

(a)

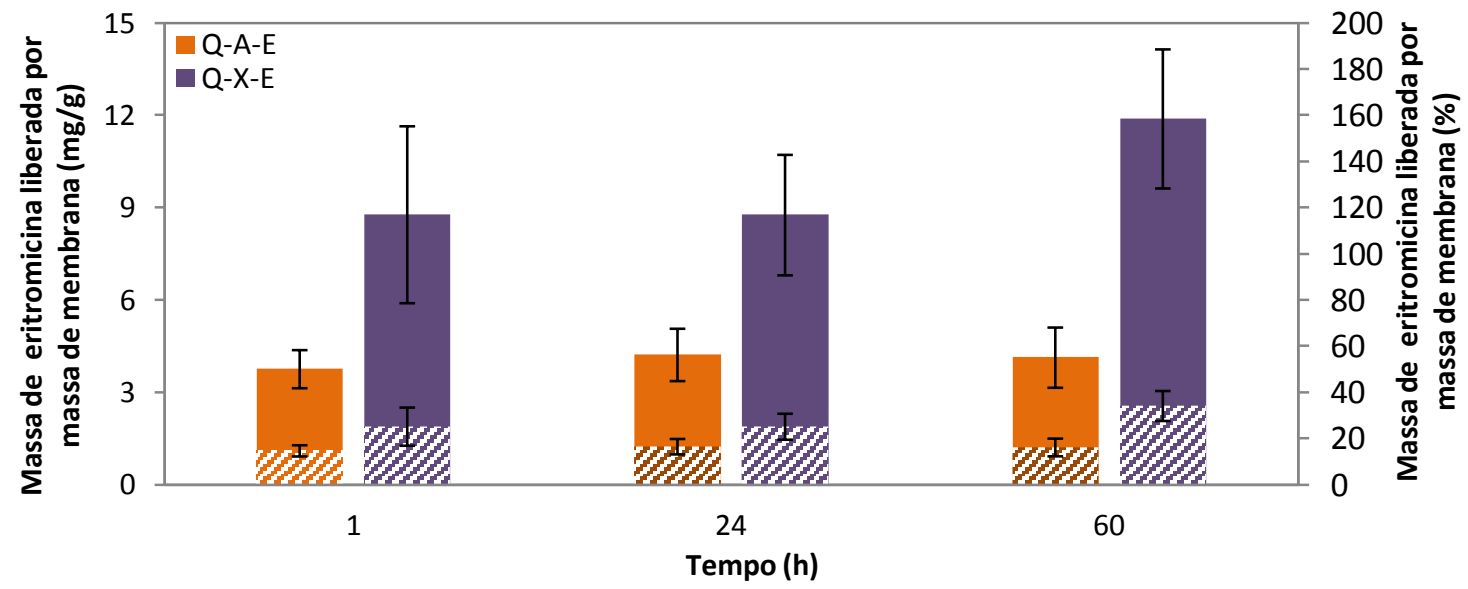

(b)

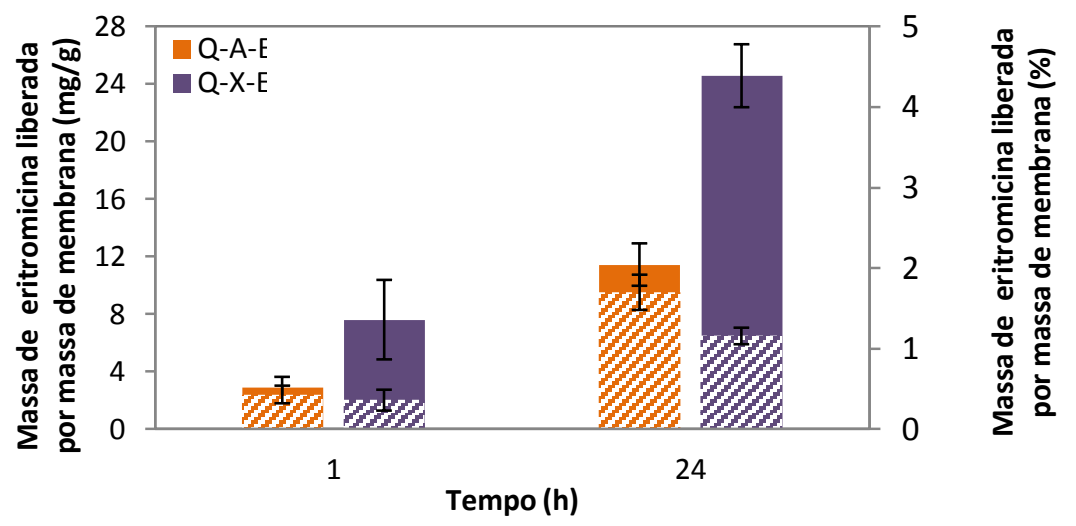

Figura 6: Quantidade de eritromicina liberada em função do tempo para os filmes constituídos de Q-A e Q-X aos quais a droga foi incorporada pelo método AD na proporção de $60 \mathrm{mg} / \mathrm{g}$ do composto (a) e pelo método IE com solução de concentração $5 \mathrm{mg} / \mathrm{mL}$ (b), em termos de $\mathrm{mg}_{\text {droga }} / \mathrm{g}_{\text {membrana }}$ (barras preenchidas) e de percentagem (barras hachuradas).

\section{CONCLUSÃO}

Observou-se que a introdução do fármaco nas matrizes não promoveu alteração em seu aspecto, e que o composto permaneceu distribuído de forma heterogênea ao longo da estrutura dos filmes. A eficiência de incorporação obtida foi maior quando se utilizou o método $\mathrm{AD}$ (máximo de 54\% para Q-X), no entanto pelo método IE maior quantidade do composto ativo ficou retida na matriz (máximo 2,1 g/g para Q-X). Devido ao tamanho relativamente grande da molécula de eritromicina, sua liberação das matrizes de Q-A e Q-X foi lenta, sendo a 
quantidade máxima de antibiótico liberada igual a $25 \mathrm{mg} / \mathrm{g}$, para Q-X quando a eritromicina foi incorporada por impregnação em solução etanólica de concentração $5 \mathrm{mg} / \mathrm{mL}$. Logo, as membranas estudadas poderiam funcionar como reservatório da droga, atuando como agente de liberação por longos períodos, sendo que o uso prolongado desses dispositivos poderia ser eficaz para a obtenção da dosagem requerida no tratamento de lesões de pele, que é de $20 \mathrm{mg} / \mathrm{g}$. Dessa forma, supõe-se que as membranas poderiam ser trocadas com menor frequência, o que favoreceria a cura da lesão e traria mais conforto ao paciente.

\section{REFERÊNCIAS}

Bueno, C. Z.; Moraes, A. M. Development of porous lamellar chitosan-alginate membranes: Effect of different surfactants on biomaterial properties. J. Appl. Polym. Sci., v.122, p.624-631, 2011.

Coviello, T.; Matricardi, P.; Marianecci, C.. Alhaique, F. Polysaccharide hydrogels for modified release formulation. J. Control. Release, v. 119, p. 5-24, 2007.

Croisier, F.; Jérôme, C. Chitosan-based biomaterials for tissue engineering. Eur. Polym. J., v. 49, p. 780-792, 2013.

Dias, A.M.A.; Braga, M.E.M.; Seabra, I.J.; Ferreira, P.; Gil, M. H.; Sousa, H.C. Development of natural-based wound dressings impregnated with bioactive compounds and using supercritical carbon dioxide. Int. J. Pharm., v. 408, p. 9-19, 2011.

Ford, J. H.; Prescott, G. C.; Iiinjiaiv, J. W.; Carou, E. L. Colorimetric determination of erythromycin. J. Anal. Chem., v. 25, n. 8, p. 1195-1197, 1953.

Lee, K. Y.; Mooney, D. J. Alginate: properties and biomedical applications. Prog. Polym. Sci., v. 37, p. 106-126, 2012.

Lima, A. C. Production methodologies of polymeric and hydrogel particles for drug delivery applications. Expert Opin. Drug Deliv., v. 9, p.231-248, 2012.

Ovington, L. G. Advances in wound dressings. Clin. Dermatol., v. 25, p. 33-38, 2007.

Penzer, R.; Ersser, S. Principles of Skin Care - A Guide for nurses and health care practitioners. Wiley-Blackwell, 2010. ISBN 978-1-4051-7087-1.

Rodrigues A. P.; Sanchez E. M. S.; da Costa A. C.; Moraes A. M. The influence of preparation conditions on the characteristics of chitosan-alginate dressings for skin lesions. J. Appl. Polym. Sci., v. 109, p. 2703-10, 2008.

Schönfeld, W.; Kirst, H. A. Macromolide antibiotics. Birkhäuser Verlag, 2002.

Veiga, I. G. Produção e caracterização de membranas de quitosana associada com outros biopolímeros para a liberação controlada de anti-inflamatórios; Tese de doutorado; Faculdade de Engenharia Química - Univ. Estadual de Campinas; Campinas, 2012.

Zahedi, P.; Razaeian, I.; Ranaei-Siadat, S. O.; Jafari, S. H.; Supaphol, P. A review on wound dressings with an emphasis on electrospun nanofibrous polymeric bandages. Polym. Adv.Technol., v. 21, p. 77-95, 2010.

Agradecimentos: À CAPES e CNPq pelo apoio financeiro e à equipe do Laboratório de Recursos Analíticos e de Calibração (LRAC/UNICAMP) pelas análises realizadas. 